\title{
Prolonged right ventricular failure after relief of cardiac tamponade
}

\author{
[Insuffisance ventriculaire droite prolongée après évacuation d'une tamponnade \\ péricardique]
}

\author{
Arnaud Geffroy MD, ${ }^{*}$ Hélène Beloeil MD, ${ }^{*}$ Erik Bouvier MD,$\dagger$ Arnaud Chaumeil MD,$\dagger$ \\ Pierre Albaladejo MD PhD, ${ }^{*}$ Jean Marty MD*
}

Purpose: To report a case of severe and fatal cardiac complication following pericardiotomy to relieve a malignant tamponade. Right ventricular (RV) failure was responsible for major hypoxemia and for a persistent shunt through a patent foramen ovale. In the absence of pulmonary embolism and coronary occlusion, possible pathophysiologic mechanisms are discussed.

Clinical features: This 53-yr-old patient presented with oropharyngeal carcinoma previously treated by chemotherapy. One month later, he showed clinical and echocardiographic signs of cardiac tamponade. He had a circumferential pericardial effusion with complete end-diastolic collapse of the right cavities. After an emergent pericardiotomy, he rapidly presented severe hypoxemia. Transesophageal echocardiography showed an akinetic and dilated right ventricle, paradoxical septal wall motion and a normal left ventricular function. A contrast study revealed a right-to-left shunt. No residual pericardial effusion was detectable. Pulmonary angiography excluded a pulmonary embolism and the coronary angiogram was normal. Troponin Ic was elevated postoperatively and peaked on day two $\left(3.78 \mu \mathrm{g} \cdot \mathrm{L}^{-1}\right)$. The patient died of refractory shock with persistent intracardiac shunt and RV akinesia on day nine.

Conclusion: Although pulmonary embolism or thrombus of a coronary vessel are the most common causes of prolonged RV failure after pericardiotomy, other mechanisms may be invoked. The possibility is raised that a rapid increase in RV tension may induce the development of muscular injury and impair coronary blood flow, despite a normal coronary angiogram. These could result in a stunned myocardium and opening of a patent foramen ovale. We hypothesize that gradual decompression of a chronic pericardial effusion might be beneficial in patients at risk.
Objectif : Rapporter un cas de complication cardiaque grave après drainage péricardique d'une tamponnade. Une défaillance ventriculaire droite était associée à une hypoxémie profonde et un shunt permanent à travers un foramen ovale perméable. En l'absence d'embolie pulmonaire et de thrombose coronaire, différents mécanismes physiopathologiques sont discutés.

Éléments cliniques : Un homme de 53 ans était atteint d'un cancer de l'oropharynx préalablement traité par chimiothérapie. Un mois plus tard, il a présenté des signes cliniques et échocardiographiques de tamponnade cardiaque. L'épanchement péricardique volumineux était circonférentiel et associé à un collapsus télédiastolique majeur des cavités droites. Après drainage chirurgical du péricarde en urgence, le patient a rapidement présenté une hypoxémie. L'échographie cardiaque transoesophagienne objectivait un ventricule droit akinétique et dilaté, un septum interventriculaire paradoxal et une fonction ventriculaire gauche normale. Une épreuve de contraste a permis de révéler un shunt droit-gauche permanent à travers un foramen ovale perméable. Aucun épanchement péricardique résiduel n'a été retrouvé. Une embolie pulmonaire ainsi qu'une thrombose coronaire ont été éliminées. Une mise en circulation de troponine lc a été notée avec un pic au deuxième jour à 3,78 $\mu \mathrm{g} \cdot \mathrm{L}^{-1}$. Le patient est décédé au neuvième jour, dans un tableau d'état de choc réfractaire avec persistance du shunt intracardiaque et de l'akinésie du ventricule droit.

Conclusion : Bien que l'embolie pulmonaire ou la thrombose coronaire soit les causes les plus fréquentes d'une défaillance ventriculaire droite prolongée après drainage péricardique, d'autres mécanismes peuvent être impliqués. Une augmentation rapide de la tension du ventricule droit a pu entraîner une atteinte du muscle cardiaque et détériorer le flux sanguin coronaire, malgré une coronarographie normale. L'état de sidération du myocarde pourrait alors permettre l'ouverture d'un foramen ovale perméable. Chez les patients à risque, une évacuation progressive des épanchements péricardiques chroniques pourrait être proposée.

From the Departments of Anesthesiology and Critical Care, ${ }^{*}$ and Cardiology, $†$ Hôpital Beaujon, Assistance Publique-Hôpitaux de Paris, Université Xavier Bichat Paris 7, Clichy Cedex, France. Address correspondence to: Dr Arnaud Geffroy, Service d'anesthésie réanimation, Hôpital Beaujon, Assistance Publique-Hôpitaux de Paris, Université Xavier Bichat Paris 7, 100 Bvd Général Leclerc, 92118 Clichy Cedex, France. Phone: 331408759 11; Fax: 33140874403 ;

E-mail: arnaud.geffroy@bjn.ap-hop-paris.fr Accepted for publication October 16, 2003.

Revision accepted February 18, 2004. 


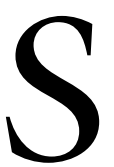

EVERAL complications have been described after pericardiocentesis or pericardiotomy to relieve cardiac tamponade. ${ }^{1,2}$ Most of these complications are directly related to the surgical technique. Other complications, such as congestive heart failure or right ventricular (RV) failure, are related to the failure of adaptative mechanisms to cope with the hemodynamic consequences of pericardial stress relief. ${ }^{3}$ We describe a case of prolonged RV failure associated with a severe atrial right-to-left shunt, in the absence of pulmonary embolism and coronary occlusion, occurring immediately after relief of a malignant cardiac tamponade. Although a few case reports describing similar scenarios have already been published, ${ }^{4}$ prolonged RV failure associated with a patent foramen ovale following pericardiotomy remains an unusual situation.

\section{Case report}

A 53-yr-old, 65-kg man presented with oropharyngeal carcinoma previously treated by chemotherapy associating 5-fluorouracil and cysplatin. No details of his medical history were known at the time he arrived at the hospital one month later. He had clinical signs of cardiac tamponade including pulsus paradoxus, turgescent jugular veins, tachycardia and dyspnea. The electrocardiogram (EKG) showed sinus tachycardia, an incomplete right bundle block and a low QRS voltage. The chest $x$-ray showed a globular heart with moderate bilateral pleural effusions. A transthoracic echocardiography (TTE) confirmed the diagnosis of a circumferential pericardial effusion with complete end-diastolic collapse of right-sided cavities. Because of the right heart failure, the patient was immediately transferred to the operating room for an emergent pericardiotomy. On arrival in the operating room, oxygen saturation $\left(\mathrm{SpO}_{2}\right)$ was $97 \%$ in room air, arterial blood pressure was $140 / 90 \mathrm{mmHg}$ and heart rate was 110 beats. $\mathrm{min}^{-1}$. After local anesthesia, a pericardiotomy was performed. As soon as the pericardium was incised, general anesthesia was induced with 20 $\mathrm{mg}$ of etomidate and $70 \mathrm{mg}$ of succinylcholine, the trachea was intubated and the lungs were ventilated mechanically on $\mathrm{FIO}_{2} 1.0$ without positive end-expiratory pressure. Anesthesia was maintained with isoflurane and fentanyl. The volume of pericardial effusion was estimated at $1500 \mathrm{~mL}$ and a drainage tube was placed. Throughout the procedure, $1500 \mathrm{~mL}$ of crystalloid were infused, blood pressures ranged between $150 / 80$ and $180 / 120 \mathrm{mmHg}$ and $\mathrm{SpO}_{2}$ was stable at $100 \%$. After recovery from anesthesia, shortly after extubation the patient became hypoxemic $\left(\mathrm{SpO}_{2}<\right.$ $80 \%$ despite supplemental oxygen) and showed sys- temic hypotension $(80 / 35 \mathrm{mmHg})$ with turgescent jugular veins. The trachea was reintubated urgently. Ten minutes after reintubation, arterial blood gas showed a $\mathrm{PaO}_{2}$ of $40 \mathrm{mmHg}$ on $\mathrm{FIO}_{2}$ 1.0.

A 12-lead EKG showed sinus rythm and an incomplete right bundle block (already present preoperatively). The chest $x$-ray showed moderate bilateral pleural effusions with no parenchymatous images. Postoperative TTE showed an akinetic and dilated RV, paradoxical septal wall motion and normal left ventricular function (the left ventricular ejection fraction was 55\%). Estimation of pulmonary arterial pressure was not possible due to the absence of tricuspid regurgitation. A contrast study revealed a right-to-left shunt which was thought to be consistent with a patent foramen ovale. No residual pericardial effusion was detectable. Troponin Ic started to raise postoperatively. The first troponin Ic value was $2.65 \mu \mathrm{g} \cdot \mathrm{L}^{-1}$ after six hours which reached a peak of $3.78 \mu \mathrm{g} \cdot \mathrm{L}^{-1}$ after $30 \mathrm{hr}$. On day four, troponin Ic returned to a normal range (normal: $<0.15 \mu \mathrm{g} \cdot \mathrm{L}^{-1}$ ).

Treatment, including mechanical ventilation and dobutamine, initially improved hemodynamic conditions markedly but hypoxemia persisted $\left(\mathrm{PaO}_{2} / \mathrm{FIO}_{2}\right.$ ratio between 80 and 100). Nitric oxide ( 5 to 30 ppm) was ineffective to improve oxygenation. Transesophageal echocardiography performed on days one, three, five and seven showed a persistent intracardiac shunt and RV akinesia. Daily EKGs showed no modification. On day three, pulmonary angiography excluded a pulmonary embolism and a coronary angiogram was normal. Right heart catheterization (performed while the patient was treated with dobutamine $10 \mu \mathrm{g} \cdot \mathrm{kg}^{-1} \cdot \mathrm{min}^{-1}$ ) showed a cardiac output of $8.5 \mathrm{~L} \cdot \mathrm{min}^{-1}$, a right atrial pressure of $17 \mathrm{mmHg}$ and $\mathrm{RV}$ pressure was $34 / 12 \mathrm{mmHg}$. Mean pulmonary artery pressure and pulmonary artery occlusion pressure were within normal limits. On day six, while the RV failure was still present, the patient developed a lung infection and a septic shock. He died of refractory shock on day nine. No autopsy was performed.

\section{Discussion}

We describe a severe and fatal cardiac complication following pericardiotomy. RV failure was responsible for major hypoxemia due to persistent shunt through a patent foramen ovale. Appropriate investigations ruled out classic causes of RV failure (i.e., pulmonary embolism, right coronary occlusion, RV compression by residual pericardial effusion or mediastinal thrombi).

$\mathrm{RV}$ failure has been described in the absence of a specific cause. Armstrong et al. were the first to describe acute RV dilation after relief of cardiac tam- 
ponade..$^{5}$ Favourable outcome was achieved after pericardiocentesis. Reports of acute RV dilation have also been described in the congenital absence of pericardium and after pericardiotomy. ${ }^{6,7}$ Anguera et al. described a case of reversible cardiogenic shock due to $\mathrm{RV}$ failure following pericardiocentesis for malignant tamponade. ${ }^{8}$ Brooker et al. recently described the successful management of global cardiac dysfunction with acute hypoxemia due to right-to-left atrial shunting with cardiopulmonary bypass following relief of a pericardial tamponade. ${ }^{4}$ Re-intervention for recurrent pericardial effusion rapidly resolved right heart failure in some of these cases. In our case, residual pericardial fluid was not associated with the persistent intracardiac shunt and RV akinesia.

Several hypotheses can be formulated to explain the pathophysiological mechanisms involved in this case. Pericardial decompression causes a sudden decrease in right atrial pressure inducing a dramatic increase in venous return, especially in spontaneously breathing patients. ${ }^{9}$ After removal of pericardial fluid, the increased venous return may allow muscular injury and dilation of one of the most distensible cardiac chambers, namely the right ventricle. Subsequent dilation of the RV is constant. A scintigraphic study found that the major increase in RV end-diastolic volume was associated with a decrease or failure to increase in RV ejection fraction shortly after relief of cardiac tamponade..$^{10}$ In the majority of cases this phenomenon is transient and no adverse consequence is observed. Moreover, the increase in RV output can lead to a rapid increase in pulmonary vascular and left atrial volumes and to pulmonary edema (especially in patients with a low compliance of the left ventricle). ${ }^{11}$

In the case we describe, the prolonged RV failure was not due to pulmonary embolism or coronary thrombosis. Nonetheless, coronary flow may be impaired by a rapid increase in RV wall tension, despite a normal coronary angiogram. This abnormal pattern of coronary flow may induce ischemic lesions (as suggested by the marked increase in troponin), creating conditions for a stunned myocardium. In this hypothesis, immediate postoperative hypotension would be a factor maintaining RV failure once the sudden RV over-distension due to decompression had already initiated it. Another explanation involves a stretch related injury possibly resulting from the abrupt cardiac distension in the presence of a more compliant pericardium. ${ }^{12}$ However, it is unlikely that such an injury would have persisted for six days. Finally, metastatic dissemination in the myocardium could have been implicated but this is an extremely rare occurrence. ${ }^{13}$ Myocardial atrophy associated with low cardiac output, which is seen in patients with chronic constrictive pericarditis after undergoing pericardiotomy can lead to global cardiac failure with overdilation. ${ }^{14}$ To avoid the consequences of a sudden increase of venous return on the right and/or left ventricular function, Sunday et al. have suggested that chronic symptomatic pericardial effusion should be relieved gradually. ${ }^{14}$

Although pulmonary embolism or coronary thrombosis are the most common causes of prolonged RV failure after pericardiotomy, other mechanisms may be invoked. We present a case raising the possibility that a rapid increase in RV tension may induce the development of muscular injury, impair coronary blood flow despite a normal coronary angiogram and create conditions for a stunned myocardium and opening of a patent foramen ovale. We hypothesize that gradual decompression of a chronic pericardial effusion may be beneficial in patients at risk of RV failure.

\section{References}

1 Snow N, Lucas AE. Subxiphoid pericardiotomy. A safe, accurate, diagnostic and therapeutic approach to pericardial and intrapericardial disease. Am Surg 1983; 49: 249-53.

2 Tsang TS, Barnes ME, Hayes SN, et al. Clinical and echocardiographic characteristics of significant pericardial effusions following cardiothoracic surgery and outcomes of echo-guided pericardiocentesis for management. Mayo Clinic experience, 1979-1998. Chest 1999; 116: 322-31.

3 Konstam MA, Levine HJ. Pulmonary edema after pericardiocentesis (Letter). N Engl J Med 1984; 310: 391.

4 Brooker RF, Testa LD, Butterworth J, Monaco TJ Jr, Nomeir AM, Oaks TE. Diagnosis and management of acute hypoxemia after drainage of massive pericardial effusion. J Cardiothorac Vasc Anesth 1998; 12: 69-71.

5 Armstrong WF, Feigenbaum H, Dillon JC. Acute right ventricular dilation and echocardiographic volume overload following pericardiocentesis for relief of cardiac tamponade. Am Heart J 1984; 107: 1266-70.

6 Payvandi MN, Kerber RE. Echocardiography in congenital and acquired absence of the pericardium. An echocardiographic mimic of right ventricular volume overload. Circulation 1976; 53: 86-92.

7 Viola $A R$. The influence of pericardiectomy on the hemodynamics of chronic constrictive pericarditis. Circulation 1973; 48: 1038-42.

8 Anguera I, Pare C, Perez-Villa F. Severe right ventricular dysfunction following pericardiocentesis for cardiac tamponade. Int J Cardiol 1997; 59: 212-4.

9 Magder $S$. More respect for the CVP (Editorial). Intensive Care Med 1998; 24: 651-3. 
10 Manyari DE, Kostuk WJ, Purves P. Effect of pericardiocentesis on right and left ventricular function and volumes in pericardial effusion. Am J Cardiol 1983; 52: 159-62.

11 Vandyke WH Jr, Cure J, Chakko CS, Gheorghiade M. Pulmonary edema after pericardiocentesis for cardiac tamponade. N Engl J Med 1983; 309: 595-6.

12 Freeman GL, LeWinter MM. Pericardial adaptations during chronic cardiac dilation in dogs. Circ Res 1984; 54: 294-300.

13 Braunwald E. Heart Disease: a Textbook of Cardiovascular Medicine, 5th ed. Phyladelphia: W.B. Saunders Company; 1997: 1794-7.

14 Sunday R, Robinson LA, Bosek V. Low cardiac output complicating pericardiectomy for pericardial tamponade. Ann Thorac Surg 1999; 67: 228-31.

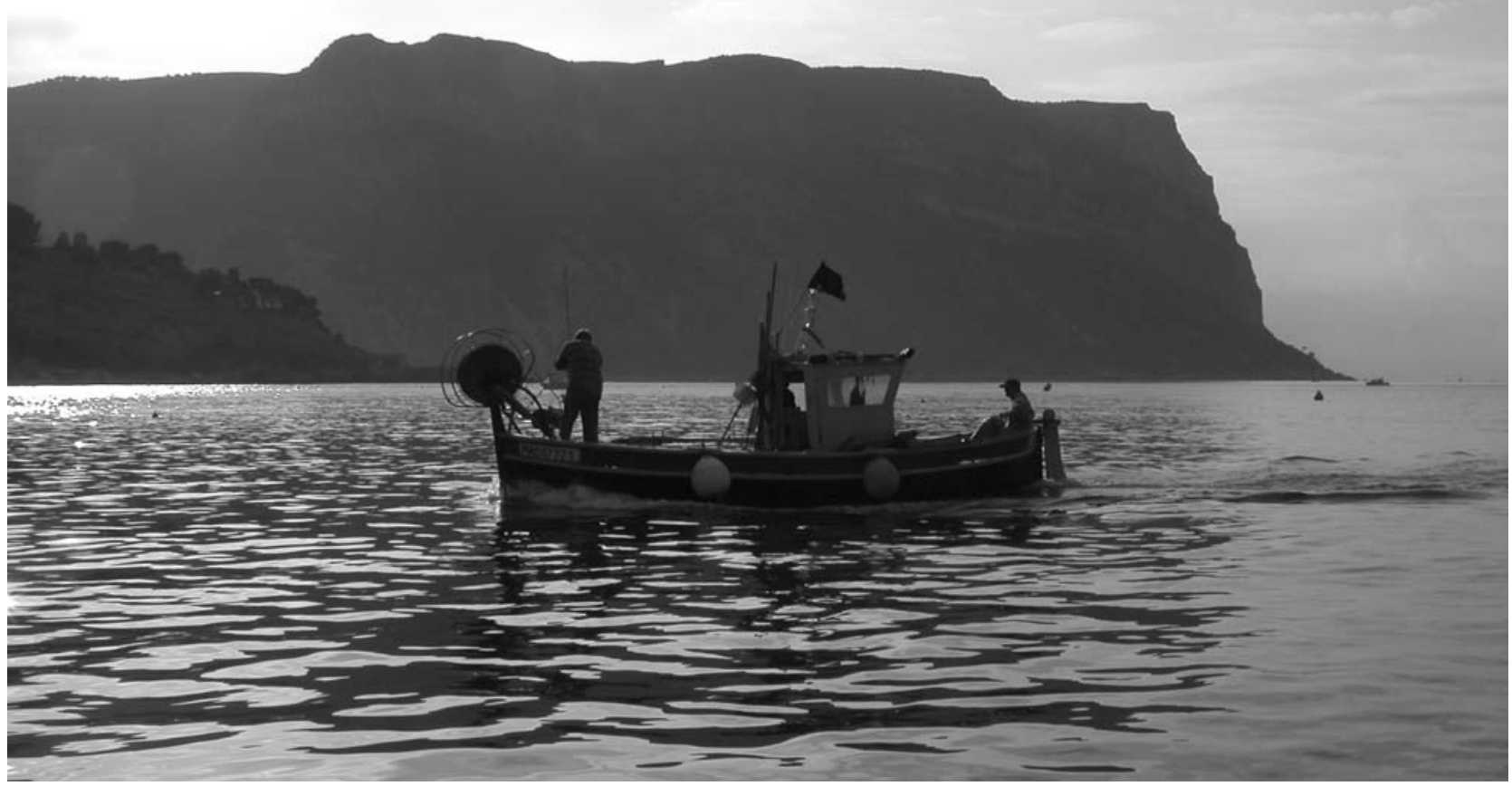

Pêcheurs port de Cassis - France 